\title{
JOE: Jogo Ortográfico Educacional
}

\section{Luan Paschoal, Tiago Bento, Tauan Velasco, Carlos Otávio Schocair, Rafael Castaneda, Talita Oliveira, Eduardo Ogasawara}

\author{
${ }^{1}$ EIC - Escola de Informática \& Computação \\ Centro Federal de Educação Tecnológica Celso Suckow Fonseca - CEFET/RJ \\ schocair, rcastaneda, toliveira, eogasawara\}@cefet-rj.br
}

\begin{abstract}
The new orthographic agreement introduces changes in the vocabulary of the Portuguese language. Although theses changes have modified a small percentage of the vocabulary, people are struggling to adapt to the new rules. Aiming to address this problem, we developed Orthographic Educational Game (JOE). JOE focuses predominantly on the rules of accents and hyphens through gamification. The game is divided into two modes: training and playing. In challenge mode, it is checked the current level of knowledge of the player in orthography measured by score. In the training mode, each word comes with a hint related to the rule that you are practicing at the moment.
\end{abstract}

Resumo. O novo acordo ortográfico introduz mudanças no vocabulário da língua portuguesa. Apesar de essas mudanças terem modificado um percentual pequeno do vocabulário, as pessoas têm passado dificuldades para se adaptar às novas regras. Visando abordar esse problema, foi desenvolvido o Jogo Ortográfico Educacional (JOE). JOE foca predominantemente nas regras de acentuação e hífen por meio de gamificação. O jogo foi dividido em dois modos: treino e desafio. No modo de desafio, é verificado o nível atual de conhecimento ortográfico do jogador medido por pontuação. No modo treinar, cada palavra vem com uma dica relacionada à regra que está praticando no momento.

\section{Introdução}

O Novo Acordo Ortográfico tem como objetivo facilitar o intercâmbio, tanto cultural como político, entre todos os países que fazem parte da Comunidade de Países de Língua Portuguesa (CPLP). Apesar da estimativa de que as mudanças no vocabulário da língua portuguesa não ultrapassem a $2 \%$ no número de palavras alteradas, alunos e professores ainda passam por dificuldades em se adaptar às novas regras (CLCP 2014).

A vigência obrigatória da nova ortografia no Brasil estava prevista para iniciar dia 31 de dezembro de 2012, mas foi adiada para janeiro de 2016 para se alinhar ao cronograma de outros países. O ministério da educação tem incentivado que os materiais escolares já estejam dentro das normas, mas ainda ocorrem dificuldades em assimilar as alterações nas regras e palavras, sendo cada vez mais necessárias novas formas de ensinar (Tarini 2011).

Os jogos educacionais estão se tornando uma opção de complemento ao ensino, sendo uma ferramenta motivadora para o aprendizado na sociedade atual. A utilização de jogos didáticos tem se mostrado eficiente no estudo e fixação do conteúdo ensinado. É uma forma de exercitar as atividades de uma maneira divertida e estimulante, além de aumentar a criatividade e atenção dos alunos (Antunes e Sabóia-Moraes 2010).

\footnotetext{
${ }^{1}$ Os autores agradecem ao CNPq e à FAPERJ pelo financiamento parcial do trabalho.
} 
Com base nesses dados, desenvolvemos o Jogo Ortográfico Educacional (JOE), que busca estimular a adaptação das pessoas às novas normas ortográficas de uma forma mais interessante. Nesse jogo, o usuário pode tanto testar seus conhecimentos, de forma avaliativa, quanto treinar, recebendo dicas sobre as regras ortográficas em um formato dinâmico e atrativo.

Este trabalho é dividido em mais três seções além desta introdução. Na seção 2, são apresentados os jogos de ortografia da língua portuguesa. Na seção 3 , é apresentado o JOE. Finalmente, a seção 4 conclui o trabalho.

\section{Jogos de Ortografia da Língua Portuguesa}

Esta seção apresenta uma visão geral do acordo ortográfico, o uso da gamificação como ferramenta de ensino e os principais trabalhos relacionados.

\subsection{Acordo Ortográfico}

O período de transição para o uso das novas regras seria até o ano de 2013 para a maioria dos países da CLPL adeptos ao acordo. Todavia, no Brasil, o prazo fora estendido para o ano de 2016. A partir dessa data, o uso das novas normas ortográficas se tornará obrigatório. Cabe salientar que o novo acordo ortográfico propõe-se a unificar exclusivamente a grafia (escrita) em língua portuguesa nos países da lusofonia, sendo mantidos, portanto, a pronúncia e o vocabulário próprios de cada país ou região.

\subsection{O uso da Gamificação como Ferramenta de Ensino}

Gamificação é um termo que possui como origem a palavra em inglês Gamification, também sendo chamado de gamificação ou ludificação. Trata-se do processo de usar características e princípios de jogos para facilitar o aprendizado e a resolução de problemas, por meio do qual, de forma lúdica, se tem a motivação de continuar a vencer os desafios do dia a dia.

Algo recorrente nas salas de aulas é a falta interesse dos alunos no que se está sendo ensinado pelos professores. A didática adotada pelas escolas tradicionais não é atraente na sociedade atual, gerando a falta de atenção dos alunos. Esses evitam estudar algo desgastante, cansativo ou complexo, pois não lhes aparenta valer a pena aprender sob esses atributos negativos, adiando ao máximo estudar tais lições (Oliveira e Alves 2005).

\subsection{Trabalhos relacionados}

Existe um conjunto de jogos clássicos que envolve a ortografia: Forca, Caça Palavras, Palavras Cruzadas e Soletrando são alguns exemplos. Esses jogos têm um aspecto lúdico e de recompensa, que estimula os alunos a estudarem mais. Entretanto, na sua essência, não têm por finalidade ensinar e nem explicar as regras gramaticais envolvidas. Já na linha de jogos computacionais educacionais, pode-se citar três: "Alfagame", "SoletrandoMob" e "OrtograFixe".

O jogo "Alfagame" (Netto e Santos 2012) é direcionado para crianças na faixa etária de 5 a 10 anos que estão em processo de alfabetização. O jogo objetiva que o jogador fixe os conteúdos previamente aprendidos da matemática e língua portuguesa de modo lúdico. Os conteúdos são abordados por meio de desafios, explorando-se a fixação do aluno no reconhecimento de consoantes, vogais e associação de palavras, bem como resoluções de operações da matemática de adição e subtração.

O Soletrandomob é um jogo no qual é apresentado o som de uma palavra e jogador deve soletrá-la corretamente, podendo solicitar dicas, como o uso da palavra em uma frase. Tal dica é uma tentativa de ajudar o jogador, inserindo a palavra em um contexto de interpretação. Ao final, é apresentada a quantidade de acertos realizados 
durante a execução do jogo. Também são apresentadas mensagens com a palavra correta, nos casos em que o jogador erra (Filho 2010). O Soletrandomob possui o mesmo princípio do JOE, que é ensinar ortografia a partir de uma metodologia que trabalhe os elementos lúdicos encontrados em jogos, mas faz isso trabalhando a ideia de memorização das palavras. Sua opção de dica somente dita uma frase que contenha a palavra atual. No JOE, a didática vai além da memorização, pois, durante o treino, a cada erro ou acerto, são ensinadas ao jogador dicas relacionadas às regras ortográficas daquela palavra e não, somente, a escrita correta.

Finalmente, o jogo "OrtograFixe" (Marques e Silva 2012) também é bem correlato, uma vez que aborda a questão da nova reforma ortográfica utilizando tablets para Android. O jogo apresenta palavras que vão se movendo de cima para baixo em velocidades diferentes. $\mathrm{O}$ usuário deve pressionar a palavra que estiver grafada de modo correto. O jogo trata regras de hifens baseadas em prefixação e recomposição. Toda vez que o usuário erra, aparece uma mensagem de erro, indicando a regra errada. No entanto, não existe modo de treinamento e desafio, deixando o lado lúdico do jogo menos interessante com muitas interrupções. A proposta do JOE é incorporar um espectro maior de regras do novo acordo e separar a etapa de treinamento da parte do jogo propriamente dito. Além disto, no JOE, o usuário ouve a palavra e deve grafá-la de modo correto, o que torna diferente a perspectiva do jogo.

\section{JOE: o Jogo}

O JOE foi desenvolvido para possibilitar o aprendizado de conceitos importantes do novo acordo ortográfico por meio de um ambiente que busque estimular o aluno a continuar dedicado em seus estudos. É uma ferramenta de prática e treino que exercita as regras ortográficas necessárias para uma escrita adequada à norma padrão da língua portuguesa, verificando, a partir de uma avaliação, onde estão ocorrendo os erros, reforçando, assim, o aprendizado.

\subsection{Regras Ortográficas Abordadas}

O jogo JOE teve como enfoque apoiar as mudanças promovidas pelo novo Acordo Ortográfico, com foco principal nas regras de acentuação e hífen, consideradas aquelas que despertam as principais dúvidas nas pessoas em geral. Além das regras gerais de acentuação e paroxítonas homógrafas, foram abordados os seguintes empregos do hífen: em palavras justapostas, em topônimos compostos, em palavras compostas; em palavras formadas por prefixação, recomposição ou sufixação.

\subsection{Arquitetura}

A arquitetura do JOE é baseada em MVC (do inglês, Model, View e Controller). O MVC permite dividir as funcionalidades do jogo em três camadas: Model, View e Controller. O Diagrama de Classes (Figura 1) foi definido na linguagem de modelagem unificada (UML). O modelo foi desenvolvido de modo incremental e consolidado após a fixação do escopo, das regras e da elaboração do formulário de avaliação experimental, visando garantir que a implementação do jogo seguisse o que fora planejado.

A camada Model é composta por seis classes destacadas em amarelo. A classe Norma é formada por uma composição de regras e representa as normas utilizadas no jogo, "Acentuação" e "Hífen". A classe Regra contém a palavra chave para identificar a regra de ortografia utilizada, uma descrição e a dificuldade que é usada na pontuação do jogador. A regra é composta por um conjunto de dicas contidas na classe DicaRegra. A classe DicaRegra contém um texto que é apresentado no modo Treinar durante cada palavra avançada, para ajudar no aprendizado das regras relacionadas. A classe Palavra 
é onde estão todas as palavras do jogo, o caminho de seus respectivos áudios, seu uso (comum ou incomum), a quantidade de erros e de visualização. Possui um identificador da regra e do modo de jogo relacionados. A classe ModoJogo apresenta os dois modos possíveis de utilização do jogo: modo Jogar e modo Treinar, importantes para definir o formato da partida. A classe Historico armazena a pontuação e o total de acertos no modo jogar e o tempo dedicado no modo treinar.

A camada View possui as telas do jogo que foram montadas em arquivos XML e carregadas em classes que estendem da classe Activity, recebem ou enviam as interações nos componentes usados, alterando valores em suas propriedades, como os sons das palavras, as mensagens e efeitos. É formada pelas classes destacadas em azul no diagrama de classes. Cada Activity possui seu respectivo arquivo XML.

A camada Controller é representada pela classe Controller. Essa é a responsável por intermediar as requisições de dados para montar a View, retornando o necessário da camada Model ou enviando para ela as alterações nas tabelas. Além disso, ela também possui os métodos que realizam as mudanças de telas, recebendo da tela inicial o modo de jogo e abrindo a tela de partida, onde realiza os seus tratamentos e registra os dados do resultado no Controller para ser mostrado no final da partida ao jogador.

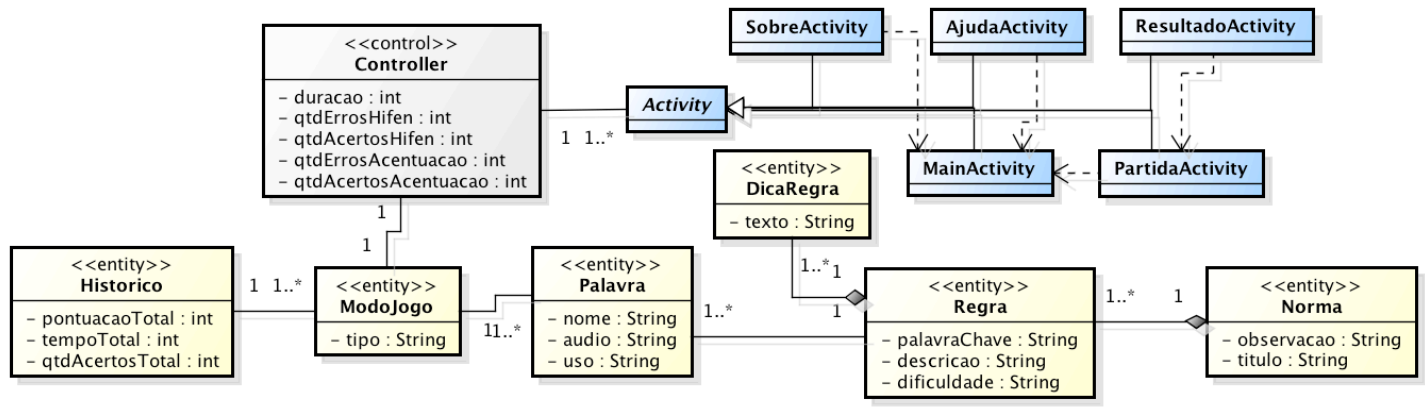

Figura 1 - Diagrama de Classes Conceitual

\subsection{Projeto de Interface Gráfica}

O jogo foi concebido para a plataforma de dispositivos móveis Android. Antes da implementação das telas do jogo, para que todos os envolvidos estivessem de acordo no quesito interface, principalmente no que se refere à usabilidade, foi apresentado um protótipo de telas (Figura 2) usando a ferramenta Mockups (Balsamiq 2014). O jogo possui três telas principais que interagem com o jogador. A inicial contém as opções de modo de jogo, além de um histórico do conjunto de acertos, a pontuação e o tempo dedicado de todas as partidas realizadas.

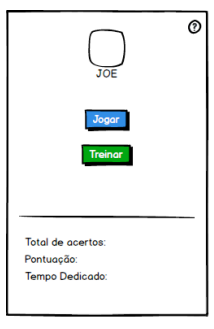

(a)

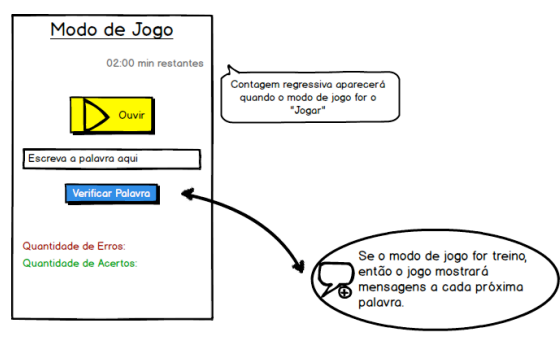

(b)

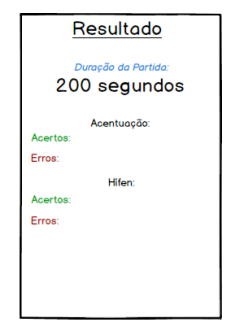

(c)

Figura 2 - Projeto de Interface: (a) tela inicial; (b) modo de jogo; (c) tela de resultado

Ao selecionar o modo, a tela com as perguntas é gerada. Foram colocadas no protótipo duas observações referentes a essa tela. Existe uma contagem regressiva caso esteja sendo executada uma avaliação. No modo treino, ao selecionar o botão de 'verificar palavra', uma mensagem de dica relacionada à regra ortográfica daquela palavra é exibida para que o jogador aprenda a cada passo. 
Quando o contador chegar a zero ou o conjunto de palavras da partida acabar, uma tela de resultado é exibida, revelando dados que foram registrados durante a execução, sendo eles a quantidade de acertos e o número de erros no hífen e na acentuação. Esses dados são importantes para o jogador identificar seu desempenho.

\subsection{Implementação}

O jogo foi construído usando a ferramenta Android Studio, desenvolvida pela Google. O Android Studio difere das outras ferramentas mais populares, como o Eclipse, usando o plugin do Android Developers Tools (ADT), por ter uma estrutura própria para o desenvolvimento para Android e utilizar nativamente o Gradle para automatizar funções que fazem parte do processo de implementação.

Para atingir uma grande quantidade de aparelhos, o jogo foi desenvolvido usando a API 8 (Android 2.2 Froyo). Ele está disponível gratuitamente no PlayStore da Google. As informações do jogo como as palavras e as mensagens foram armazenadas múltiplas tabelas em um único arquivo no disco no aparelho por meio da biblioteca SQLite.

\section{Conclusões}

O JOE é uma ferramenta educacional baseada em gamificação voltada ao aprendizado no novo acordo ortográfico. A ferramenta é gratuita e está disponível no Play Store do Google. Na próxima etapa serão conduzidos experimentos com alunos tanto de ensino médio-técnico quanto de graduação. A partir dos experimentos, espera-se observar se a nossa abordagem, baseada no ensino por meio de jogos, para ortografia consegue trazer alguns resultados importantes e nos direcionar para próximos desenvolvimentos para a língua portuguesa.

\section{Referências}

Antunes, A., Sabóia-Moraes, S., (2010), "O jogo educação e saúde: Uma proposta de mediação pedagógica no ensino de ciências", Experiências no Ensino de Ciências, Porto Alegre, v. 5, n. 2, p. 55-70.

Balsamiq, (2014), Balsamiq Mockups, http://balsamiq.com/products/mockups.

CLCP, (2014), Acordo Ortográfico da Língua Portuguesa, http://www.cplp.org/id176.aspx.

Filho, A. F. G. de M., (2010), "SoletrandoMob: Um Jogo Educacional Voltado para o Ensino da Ortografia na Língua Portuguesa em Plataformas Móveis". In: $V$ CONNEPI-2010

Marques, D. L., Silva, A. P. S., (2012), "OrtograFixe - Um jogo para apoiar o ensinoaprendizagem das regras da nova reforma ortográfica". In: Anais dos Workshops do XXIII Congresso Brasileiro de Informática na Educação

Netto, D. P. da S., Santos, M. W. A. dos, (2012), "AlfaGame: Um Jogo para auxílio no processo de alfabetização". In: XXIII Congresso Brasileiro de Informática na Educação

Oliveira, C. B. E. de, Alves, P. B., (2005), "Ensino fundamental: papel do professor, motivação e estimulação no contexto escolar", Paidéia (Ribeirão Preto), v. 15, n. 31 (ago.), p. 227-238.

Tarini, A. M., (2011), "Idas e vindas do acordo ortográfico brasileiro: construindo limites para uma língua des-limite", O VII Encontro Internacional de LetrasLiteratura e Linguística, p. 58. 